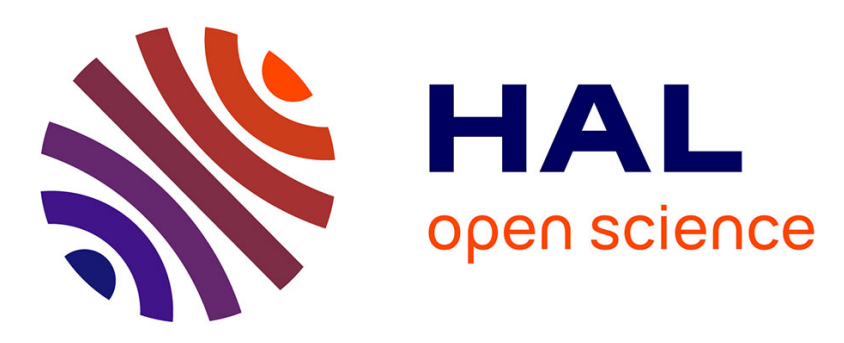

\title{
Study of the fast photoswitching of spin crossover nanoparticles outside and inside their thermal hysteresis loop
}

Geoffrey Gallé, Céline Etrillard, Jérôme Degert, François Guillaume, Jean-François Létard, Eric Freysz

\section{To cite this version:}

Geoffrey Gallé, Céline Etrillard, Jérôme Degert, François Guillaume, Jean-François Létard, et al.. Study of the fast photoswitching of spin crossover nanoparticles outside and inside their thermal hysteresis loop. Applied Physics Letters, 2013, 102 (6), pp.063302 (1-4). 10.1063/1.4792527 . hal00795299

\section{HAL Id: hal-00795299 \\ https://hal.science/hal-00795299}

Submitted on 6 Mar 2018

HAL is a multi-disciplinary open access archive for the deposit and dissemination of scientific research documents, whether they are published or not. The documents may come from teaching and research institutions in France or abroad, or from public or private research centers.
L'archive ouverte pluridisciplinaire HAL, est destinée au dépôt et à la diffusion de documents scientifiques de niveau recherche, publiés ou non, émanant des établissements d'enseignement et de recherche français ou étrangers, des laboratoires publics ou privés. 


\section{AIP Appiled Physics \\ Letters}

\section{Study of the fast photoswitching of spin crossover nanoparticles outside and inside their thermal hysteresis loop}

G. Gallé, C. Etrillard, J. Degert, F. Guillaume, J.-F. Létard et al.

Citation: Appl. Phys. Lett. 102, 063302 (2013); doi: 10.1063/1.4792527

View online: http://dx.doi.org/10.1063/1.4792527

View Table of Contents: http://apl.aip.org/resource/1/APPLAB/v102/i6

Published by the American Institute of Physics.

\section{Related Articles}

Study of the fast photoswitching of spin crossover nanoparticles outside and inside their thermal hysteresis loop APL: Org. Electron. Photonics 6, 28 (2013)

Optimal switching using coherent control

Appl. Phys. Lett. 102, 041107 (2013)

Optical bistability based on Bragg grating resonators in metal-insulator-metal plasmonic waveguides AlP Advances 3, 012106 (2013)

Bistability patterns and nonlinear switching with very high contrast ratio in a 1550nm quantum dash semiconductor laser

Appl. Phys. Lett. 101, 161117 (2012)

All-optical on-chip dynamic frequency conversion

Appl. Phys. Lett. 101, 141119 (2012)

\section{Additional information on Appl. Phys. Lett.}

Journal Homepage: http://apl.aip.org/

Journal Information: http://apl.aip.org/about/about_the_journal

Top downloads: http://apl.aip.org/features/most_downloaded

Information for Authors: http://apl.aip.org/authors

\section{ADVERTISEMENT}

\section{AIP Applied Physics Letters}

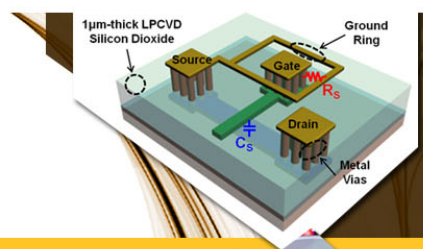

\section{SURFACES AND} INTERFACES

Focusing on physical, chemical, biological structural, optical, magnetic and electrical properties of surfaces and interfaces, and more..

\section{EXPLORE WHAT'S NEW IN APL}

SUBMIT YOUR PAPER NOW!
ENERCY CONVERSION AND STORACE 


\title{
Study of the fast photoswitching of spin crossover nanoparticles outside and inside their thermal hysteresis loop
}

\author{
G. Gallé, ${ }^{1}$ C. Etrillard, ${ }^{2}$ J. Degert, ${ }^{1}$ F. Guillaume,${ }^{3}$ J.-F. Létard, ${ }^{2}$ and E. Freysz ${ }^{1, a)}$ \\ ${ }^{1}$ Université de Bordeaux, LOMA, UMR-CNRS 5798, 351 cours de la Libération, 33405 Talence Cedex, France \\ ${ }^{2}$ CNRS, Université de Bordeaux, ICMCB, UPR CNRS 9048, 87 Avenue du Docteur Albert Schweitzer, \\ 33608 Pessac Cedex, France \\ ${ }^{3}$ Université de Bordeaux, ISM, UMR CNRS 5255, 351 cours de la Libération, 33405 Talence Cedex, France
}

(Received 5 October 2012; accepted 4 February 2013; published online 13 February 2013)

\begin{abstract}
We have studied the low spin to high spin phase transition induced by nanosecond laser pulses outside and within the thermal hysteresis loop of the $\left[\mathrm{Fe}(\mathrm{Htrz})_{2} \operatorname{trz}\right]\left(\mathrm{BF}_{4}\right)_{2}-\mathrm{H}_{2} \mathrm{O}$ spin crossover nanoparticles. We demonstrate that, whatever the temperature of the compound, the photo-switching is achieved in less than $12.5 \mathrm{~ns}$. Outside the hysteresis loop, the photo-induced high spin state remains up to $100 \mu \mathrm{s}$ and then relaxes. Within the thermal hysteresis loop, the photo-induced high spin state remains as long as the temperature of the sample is kept within the thermal loop. A Raman study indicates that the photo-switching can be completed using single laser pulse excitation. (C) 2013 American Institute of Physics. [http://dx.doi.org/10.1063/1.4792527]
\end{abstract}

Optical switching of spin crossover (SCO) materials has recently been attracting great interest because of the large prospects in the development of future optical memories. ${ }^{1}$ The optical switching of these materials has been recorded at both low and high temperatures. ${ }^{2-5}$ It is often accompanied by a phase transition. Since most of the physical properties of the material are modified during a phase transition, this indicates that they can be controlled and modulated by light. However, whatever the physical process that drives the phase transition, it evolves with a given speed $v$ that links the size of the system $L$ to the switching-time $t_{s}\left(t_{s}=L / v\right) . t_{s}$ is the time required by the phase transition to take place over the whole system. Therefore, to speed up the photo-switching, it may be interesting to split the volume $V \sim L^{3}$ of the material that is dispersed in a host matrix, in $N$ sub-volumes. The characteristic size of these sub-volumes $L_{c}=L / N$ will, therefore, divide the photo-switching time $t_{s}$ by $N$. In practice, the reduction of the size is limited by the capability to synthesize submicrometric or even nanometric SCO particles. However, at the nanoscale, the macroscopic properties of the system and, for instance, the phase diagram and phase transition are often modified. ${ }^{6}$ Here again, SCO compounds are of particular interest since it has been shown that the macroscopic properties of the system can be easily kept up to a $10-30 \mathrm{~nm}$-scale. ${ }^{7,8}$ Photo-switching of such SCO nanoparticles (NPs) is thus expected to occur on a very small time scale. Along this line, it has recently been shown, using femtosecond time resolved optical spectroscopy, that the first step of photo-switching in a molecular nanocrystals occurs in $\sim 1$ ps. ${ }^{9}$ While this study is very interesting, many questions have still to be addressed. At first, does this process occur in other SCO nano-crystals which, for example, exhibit a thermal hysteresis loop? Second, besides the switching of the optical properties, does the photo-switching induces a phase transition? Indeed, it has already been shown that in some SCO crystals the optical properties may be switched without inducing a phase transition. Finally, what

${ }^{\text {a)} E l e c t r o n i c ~ m a i l: ~ e . f r e y s z @ l o m a . u-b o r d e a u x 1 . f r . ~}$ is the characteristic time scale during which the photoswitching is maintained within the nano-crystal? Indeed, if the nano-crystal recovers its initial state, it does not require to be excited again during this time scale.

In this paper, we report on the low spin (LS) state $\rightarrow$ high spin (HS) state photo-switching recorded in NP of $\left[\mathrm{Fe}(\mathrm{Htrz})_{2}\right.$ trz $]\left(\mathrm{BF}_{4}\right)_{2}-\mathrm{H}_{2}$ compound with $\mathrm{Htrz}=1,2,4-4 \mathrm{H}-$ triazole and $\operatorname{trz}=$ the deprotonated triazolato $+(-)$ ligand. These NPs exhibit a large hysteresis loop at room temperature. Our time resolved reflection spectroscopy indicates that the LS $\rightarrow$ HS photo-switching by a nanosecond pulse is completed within our experimental resolution $(\sim 12.5 \mathrm{~ns})$. Outside the thermal hysteresis loop, the particles recover their initial state in about $10 \mathrm{~ms}$, whereas within the hysteresis loop, the photo-excited NP remains in the HS state. Raman spectroscopy of the NP performed within the thermal hysteresis loop before and after the photo-excitation indicates that all the photo-excited NPs are brought in the HS state. This stresses that within these NPs, the photo-induced phase transition is completed in less than $12.5 \mathrm{~ns}$.

The synthesis of $\left[\mathrm{Fe}(\mathrm{Htrz})_{2} \operatorname{trz}\right]\left(\mathrm{BF}_{4}\right)_{2}-\mathrm{H}_{2} \mathrm{O} \mathrm{SCO}$ compound has been reported by Kröber et al. ${ }^{10}$ More recently, it has been shown that NPs of this compound can also be obtained by different means. ${ }^{11,12}$ The synthesis of the NP used hereafter will be published elsewhere and has already been reported. ${ }^{13}$ Fig. 1 presents an image of the NPs recorded using transmission electronic microscopy (TEM). The NPs have a parallelepiped shape with a long and short axes. The size dispersions along the $35 \mathrm{~nm}$ and $115 \mathrm{~nm}$ short and long axes are about $5 \mathrm{~nm}$ and $10 \mathrm{~nm}$, respectively. Fig. 2(a) shows thermal hysteresis we have recorded using a powder of these NPs. This hysteresis extends over $\sim 30 \mathrm{~K}$ and it is centered above room temperature. In the LS state, the powder of NPs is pink, and becomes white in the HS state. Actually, this powder is composed of aggregates, a few microns in diameter, of packed NPs. The evolution of the optical spectrum reflected by the powder of NPs is presented in Fig. 2(b). These spectra are dependent on the used light source and the optical spectrometer. However, the difference between the spectra 


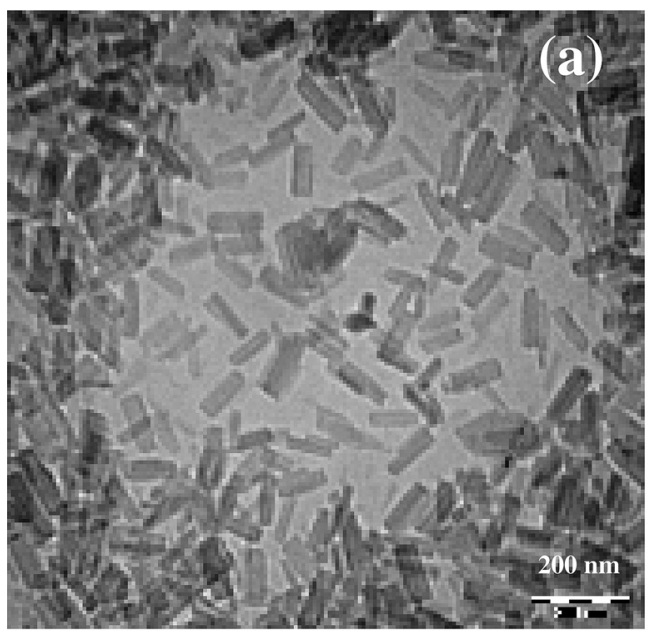

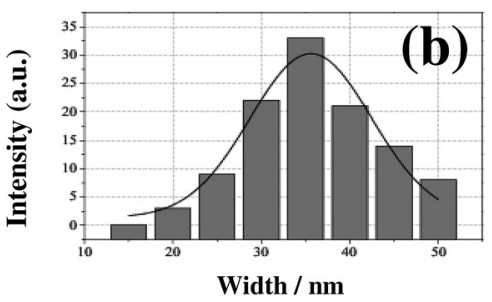

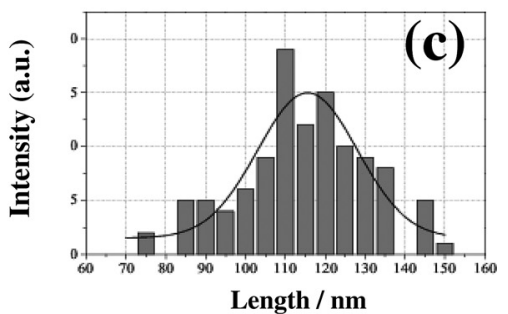

FIG. 1. (a) TEM image of the nanoparticles. (b) Width distribution of the nanoparticles. (c) Length distribution of the nanoparticles. recorded in the LS and the HS states reveals the presence of two bands. The first one is centered at $\lambda \sim 550 \mathrm{~nm}$, about the d-d: ${ }^{1} A_{1} \rightarrow{ }^{1} T_{1}$ transition of this iron(II) complex. The second one, which is weaker and negative, is centered at $\lambda \sim 780 \mathrm{~nm}$, about the d-d: ${ }^{5} T_{2} \rightarrow{ }^{5} E$ transition. ${ }^{3}$ It has previously been shown that the evolution of the reflected spectrum versus the temperature of the compound accurately matches the fraction $\gamma_{H S}$ of NPs in the HS state. ${ }^{4}$ Therefore, once a calibration between reflected optical spectrum and $\gamma_{H S}$ has been performed, we have a very simple mean to evaluate the magnetic state of a studied SCO compound. Hereafter, the magnetic state has been calibrated with respect to the reflectivity of the sample recorded at $\lambda=500 \mathrm{~nm}$. The reflectivity change is $\Delta R=0$ (resp. $\Delta R=1$ ), if the sample is in the LS (resp. HS) state.

To study the kinetics of the photoswitching on the nanosecond to millisecond time scale, we used a time resolved reflection set-up. This set-up has been described elsewhere. ${ }^{14}$ In short, the sample is excited by a Nd:YAG laser that yields $6 \mathrm{~ns}$ pulses centered at $\lambda=355 \mathrm{~nm}$. The excitation pulses are slightly focussed on the sample. To record the evolution of the sample reflectivity, we used a femtosecond laser oscillator that delivers, at $80 \mathrm{MHz}$ repetition rate, $200 \mathrm{fs}$ pulses centered at $\lambda=500 \mathrm{~nm}$. These femtosecond pulses are reflected by the sample and then are focused on a fast photo-diode
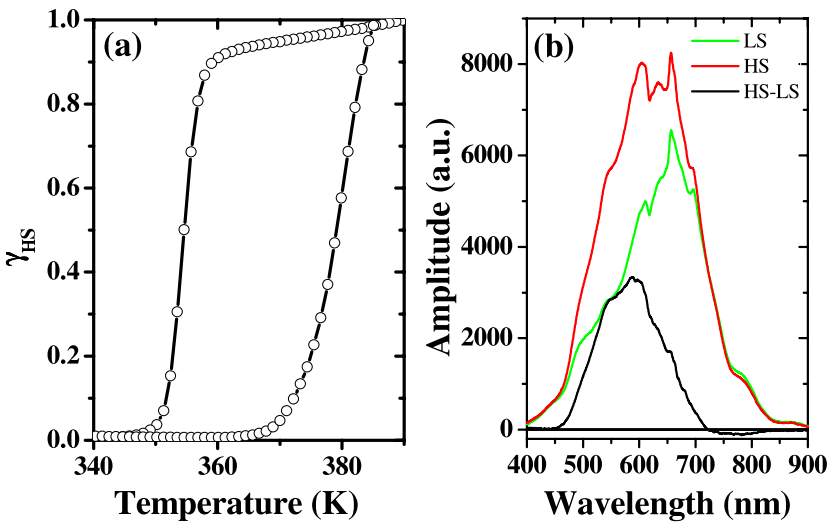

FIG. 2. (a) Thermal hysteresis loop recorded using the nanoparticles. (b) Reflectivity spectra of the nanoparticles in the HS and LS states. Solid line in black, the spectrum obtained by subtracting the LS spectrum from the HS spectrum.
( $\sim 1 \mathrm{~ns}$ rise-time), which is connected to a $20 \mathrm{GHz}$ sampling oscilloscope. This sampling scope is triggered by the Nd:YAG laser pulse. This set-up makes it possible to record the evolution of the amplitude of the reflected femtosecond pulse from the nanosecond up to the second time-scale. Its temporal resolution is limited to $\sim 12.5 \mathrm{~ns}$ owing to the pulse repetition rate of our femtosecond laser oscillator.

The evolution of the reflectivity of the sample of NPs, when its temperature is set at $T=338 \mathrm{~K}$ below the thermal hysteresis loop, upon excitation by the a single Nd:YAG pulse of $20 \mathrm{~mJ} \mathrm{~cm}^{-1}$ is presented in Fig. 3(a). This figure makes it possible to catch the evolution of the sample in the $10 \mathrm{~ns}-20 \mathrm{~ms}$ time scale. One can notice that upon laser excitation, the reflectivity of our sample rapidly changes within the first $20 \mathrm{~ns}$ and then remains almost unchanged up to $100 \mu \mathrm{s}$. After $100 \mu \mathrm{s}$, the reflectivity starts to decay exponentially and the sample recovers its initial state after $\sim 10 \mathrm{~ms}$. In Fig. 3(b), we have zoomed on the temporal evolution of the sample during the first $200 \mathrm{~ns}$ upon the laser excitation. Within our experimental uncertainties, we could well reproduce our experimental data considering the reflectivity of the sample is described by an exponential growth law. The associated constant time is found to be $\tau \sim 12 \pm 5 \mathrm{~ns}$. This time constant is very close to our experimental resolution
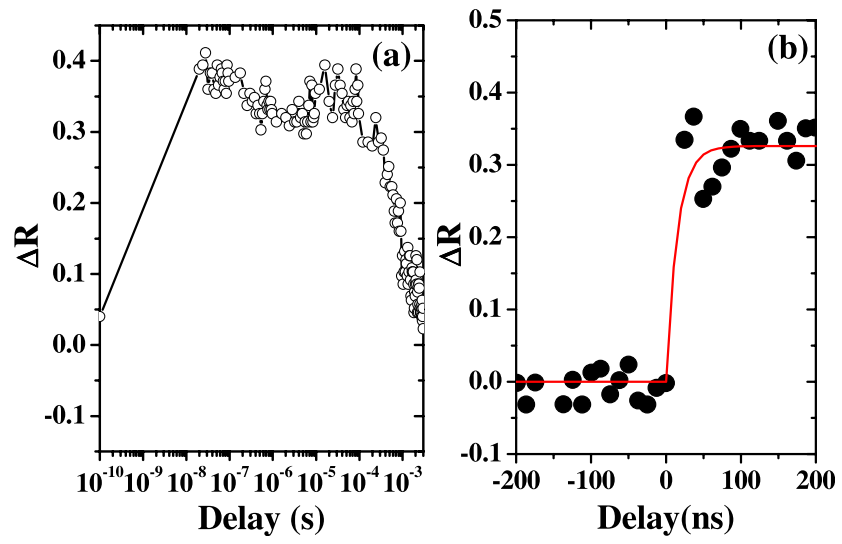

FIG. 3. (a) Evolution of the reflectivity of the sample at $T=338 \mathrm{~K}$ in the LS state after an excitation by a single laser pulse. The temperature of the sample is initially below the thermal hysteresis loop. (b) Zoom on the reflectivity change on the nanosecond time scale $(\Delta R=1$, if the sample is brought in the HS state). The filled circles represent the experimental data. The solid line represents a fit considering an exponential growth law. 
indicating that the photo-switching of the sample is likely to occur in less than $12.5 \mathrm{~ns}$.

We have performed the same experiment when the sample is in the LS state but within the thermal hysteresis loop. Under such condition, the sample in the HS state should remain in this state. The evolution of the sample reflectivity when its temperature is set to $T=365 \mathrm{~K}$ after two successive single-pulse excitations is shown in Figs. 4(a) and 4(b). On Fig. 4(a), one can notice that the reflectivity of the sample almost instantaneously increases upon laser excitation. The transient reflectivity recorded during the first 100 ns upon the laser excitation resembles to the one in Fig. 3(b). This indicates that the photo-switching time of the sample is here again below $12.5 \mathrm{~ns}$. On the longer time scale, Fig. 4(a) indicates a very small but steady increase. Fig. 4(b) also shows that the second excitation pulse induces a very weak change of the sample reflectivity, which is $\Delta R=0.5 \pm 0.04$ within our experimental uncertainties. It indicates that with the laser fluence we used $\left(\sim 20 \mathrm{~mJ} \mathrm{~cm}^{-2}\right)$, the second laser pulse does not improve the LS $\rightarrow$ HS photo-switching. Additional experiments not shown here indicate that when the temperature of the sample was set at $T=355 \mathrm{~K}$ (resp. $T=360 \mathrm{~K}$ ), the amplitude of the reflectivity change decreased to $\Delta R=0.35 \pm 0.04$ (resp. $\Delta R=0.42 \pm 0.04$ ). However, the recorded temporal behavior is similar. We attribute the evolution of the reflectivity on the longer time scale to the aggregation of the NPs. This phenomenon has been detailed elsewhere. ${ }^{15}$ In short, due to the small penetration depth at the excitation wavelength within the NPs aggregates, only the NPs at the surface of the aggregates absorb a large amount of the laser beam energy. Hence, upon the laser excitation, it is these NPs at the surface of the aggregates that are first switched from the LS to the HS state. This accounts for the change of the reflectivity we recorded during the first $12.5 \mathrm{~ns}$ upon excitation. Later on, the laser energy absorbed by NPs at the surface of the aggregate is released into heat that diffuses within the aggregate. This results in a temperature increase $\Delta T$ of the whole aggregate. But $\Delta T$ decreases as the heat diffuses towards the center of the aggregate. ${ }^{15}$ When the temperature of the NPs within the aggregate reaches the top of the ascending branch of the thermal hysteresis loop, they are switched from the LS to the HS
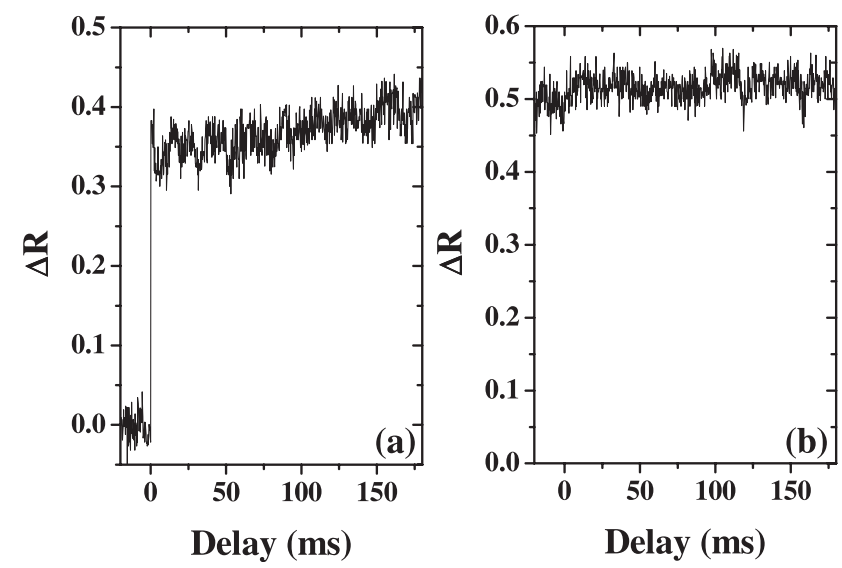

FIG. 4. (a) Evolution of the reflectivity of the sample at $T=365 \mathrm{~K}$ after an excitation by a single pulse. The sample is set in the LS state within its thermal hysteresis loop. (b) Evolution of the reflectivity of the sample when the sample is excited by a second pulse. state. This accounts for the increase of the reflectivity of our sample on the longer time scale. However, if the energy deposited by the laser beam at the surface of the aggregate is not sufficient, the NPs close to the center of aggregate are not switched. Hence, as shown in Fig. $4, \Delta R$ is clamped to $\sim 0.5$. It indicates that, indeed, only a part of the NPs within the aggregates has been switched from the LS to the HS state.

To confirm the impact of the aggregation of NPs on the photo-switching and to characterize in more detail the state of the NPs prior and after excitation, we have also performed a Raman study. The experimental set-up we used is described elsewhere. ${ }^{16}$ The SCO NPs were highly dispersed on a microscope fused silica cover plate. This sample was inserted in a thermally regulated oven. To avoid the aggregation effect, we checked that within the continuous laser spot, a few microns in diameter, used to perform the Raman spectroscopy, the NPs were highly dispersed (see Fig. 1). Then, we measured the Raman spectrum of the NPs in the LS and HS states. Fig. 5 indicates that in the $100 \mathrm{~cm}^{-1}-400 \mathrm{~cm}^{-1}$ range, the LS and HS states can be distinguished by their Raman spectra. Indeed, the two Raman bands centered at $220 \mathrm{~cm}^{-1}$ and $280 \mathrm{~cm}^{-1}$ disappear when the temperature of the sample is set in the HS state. Then, we have excited our sample using the Nd:YAG pulse centered at $\lambda=355 \mathrm{~nm}$. The laser fluence on the sample was $\sim 10 \mathrm{~mJ} \mathrm{~cm}^{-2}$. Prior to laser excitation, the temperature of the sample was set at $340 \mathrm{~K}$, below the thermal hysteresis loop. Then, the temperature was slowly increased up to $T=365 \mathrm{~K}$. The sample is, therefore, set in the LS state, in the middle of the thermal hysteresis loop. The Raman spectra of the sample before and after its excitation by a single Nd:YAG laser pulse are shown in Fig. 5. One can readily notice that the Raman spectrum of the photo-excited sample is almost similar to the Raman spectrum of the sample in the HS state. This experiment also indicates that, for diluted NPs, we were able to achieve a complete $\mathrm{LS} \rightarrow \mathrm{HS}$ state photo-switching with only $10 \mathrm{~mJ} \mathrm{~cm}^{-2}$, whereas it was only partial using $\sim 20 \mathrm{~mJ} \mathrm{~cm}^{-2}$ on the NPs aggregates. This stresses that, as we previously mentioned, when the particles are packed or aggregated, the properties of the sample are modified. Finally, to check the robustness of our sample to optical photo-switching, we

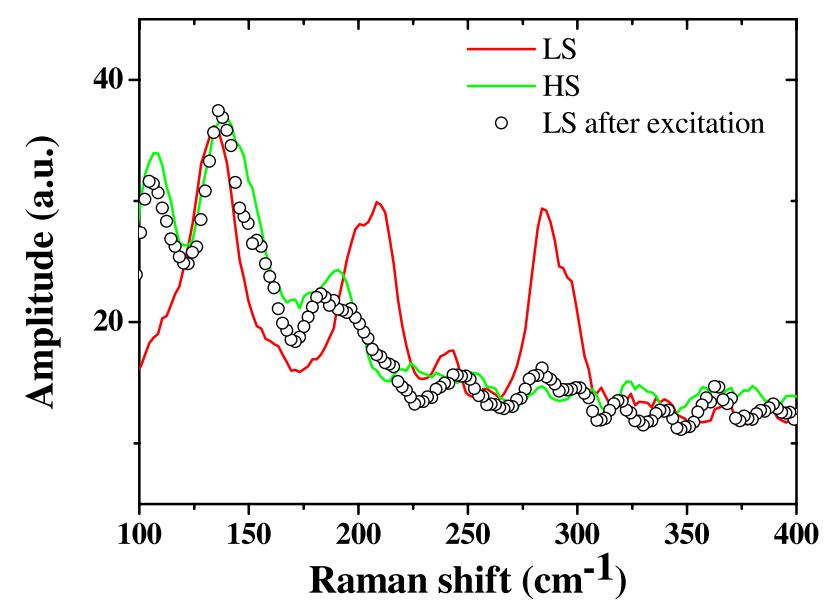

FIG. 5. Raman spectra of the sample in the LS and HS states. The circles present the Raman spectrum of the sample initially set within the LS state in its thermal hysteresis loop, and then excited by a single laser pulse. 
repeated this experiment more than 100 times and did not record any particular change. This result is of particular interest for practical applications of these SCO NPs in optically photo-switchable materials.

In conclusion, we have presented experimental results demonstrating that the LS $\rightarrow$ HS state switching of NPs induced by $6 \mathrm{~ns}$ laser pulses occurs in less than $12.5 \mathrm{~ns}$. We have shown that, within the thermal hysteresis loop of these SCO NPs, a single nanosecond laser pulse can complete the $\mathrm{LS} \rightarrow \mathrm{HS}$ state photoswitching. These results indicate that these SCO NPs are robust against photo-excitation and offer many interesting prospects for optical data recording.

This work has been supported by the Conseil Région Aquitaine (MatTS), the GIS-Advanced Materials in Aquitaine (AMA), the ANR Agency (Ultimate-09-BLAN-045198 and RMNP 01901 “OptoMaTS”).

${ }^{1}$ See for general reviews, Spin Crossover in Transition Metal Compounds I-III, Topics in Current Chemistry Special Topic Vols. 233-235, edited by P. Gütlich and H. A. Goodwin (Springer, 2004).

${ }^{2}$ S. Decurtins, P. Gütlich, C. P. Köher, H. Spiering, and A. Hauser, Chem. Phys. Lett. 105, 1 (1984).
${ }^{3}$ A. Hauser, Chem. Phys. Lett. 124, 543 (1986).

${ }^{4}$ E. Freysz, S. Montant, S. Létard, and J.-F. Létard, Chem. Phys. Lett. 394, 318 (2004).

${ }^{5}$ S. Bonhommeau, G. Molnár, A. Galet, A. Zwick, J.-A. Real, J. J. McGarvey, and A. Bousseksou, Angew. Chem., Int. Ed. 44, 4069 (2005).

${ }^{6}$ K. Binder and D. P. Landau, Phys. Rev. B 30, 1477 (1984).

${ }^{7}$ Th. Forestier, A. Kaiba, S. Pechev, D. Denux, Ph. Guionneau, C. Etrillard, N. Daro, E. Freysz, and J.-F. Létard, Chem. - Eur. J. 15, 6122 (2009).

${ }^{8}$ A. Bousseksou, G. Molnar, L. Salmon, and W. Nicolazzi, Chem. Soc. Rev. 40, 3313 (2011).

${ }^{9}$ R. Bertoni, M. Lorenc, A. Tissot, M. Servol, M. L. Boillot, and E. Collet, Ang. Chem., Int. Ed. 51, 7485 (2012).

${ }^{10}$ J. Kröber, J.-P. Audire, R. Claude, E. Codjovi, O. Kahn, J. G. Haasnoot, F. Grolire, C. Jay, A. Bousseksou, J. Linars, F. Varret, and A. GonthierVassal, Chem. Mater. 6, 1404 (1994).

${ }^{11}$ E. Coronado, J. R. Galn-Mascars, M. Monrabal-Capilla, J. Garca-Martnez, and P. Pardo-Ibez, Adv. Mater. 19, 1359 (2007).

${ }^{12}$ S. Titos-Padilla, J. M. Herrera, X.-W. Chen, J. J. Delgado, and E. Colacio, Angew. Chem., Int. Ed. 50, 3290 (2011).

${ }^{13}$ C. Etrillard, Ph.D. thesis, Université Bordeaux 1, 20 December 2011.

${ }^{14}$ G. Galle, D. Deldique, J. Degert, Th. Forestier, J. F. Létard, and E. Freysz, Appl. Phys. Lett. 96, 041907 (2010).

${ }^{15}$ O. Fouché, J. Degert, G. Jonusauskas, N. Daro, J. F. Létard, and E. Freysz, Phys. Chem. Chem. Phys. 12, 3044 (2010).

${ }^{16}$ Y. A. Tobon, C. Etrillard, O. Nguyen, J.-F. Létard, V. Faramarzi, J.-F. Dayen, B. Doudin, D. M. Bassani, and F. Guillaume, Eur. J. Inorg. Chem. 2012, 5837. 